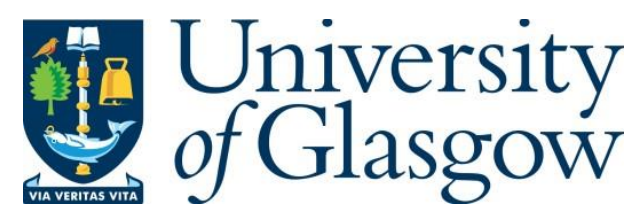

Hladek, L., Brimijoin, W. and Porr, B. (2017) Electro-oculography based horizontal gaze tracking: A perspective for attention-driven hearing aids. Journal of the Acoustical Society of America, 141(5), p. 3571.

There may be differences between this version and the published version. You are advised to consult the publisher's version if you wish to cite from it.

http://eprints.gla.ac.uk/147148/

Deposited on: 19 September 2017

Enlighten - Research publications by members of the University of Glasgow http://eprints.gla.ac.uk 


\section{Electro-oculography based horizontal gaze tracking: A perspective for attention-driven hearing aids}

Lubos Hladek and W. Owen Brimijoin MRC / CSO Inst. of Hearing Res. (Scottish Section), Glasgow Royal Infirmary, 10-16 Alexandra Parade, New Lister Bldg. 3L, Glasgow Royal Infirmary, Glasgow G31 2ER, United Kingdom, lubos.hladek@nottingham.ac.uk Bernd Porr School of Eng., Univ. of Glasgow, Glasgow, United Kingdom

Users of hearing aids with standard directional microphones can have difficulties in complex listening situations such as multi-talker environments because they must turn their heads to follow conversations that move rapidly from one talker to the next. The use of gaze-pointed hearing aid directionality has been suggested as a way to potentially alleviate this problem [Kidd et al. (2013); J. Acoust. Soc. Am. 2013; 133(3): EL202-7.] However, to arrive at a practical and usable device, there is the need for unobstructive and mobile technology for gaze tracking. Here, we propose and evaluate an algorithm for estimating eye-gaze angle based solely on the single channel electro-oculogram (EOG), which can be obtained directly from the ear canal using conductive hearing aid molds. In contrast to conventional techniques, we use an algorithm which calculates the absolute eye angle by statistical analysis of the saccades. This results in robust long term performance where predicted eye angles significantly correlate with actual eye angles. This opens up the possibility of an attention driven beam-former for hearing aids without the need for eye-tracking goggles.

[This work was supported by the Medical Research Council [grant number U135097131], Chief Scientist Office (Scotland) and Oticon Foundation.] 